International Journal of Automotive and Mechanical Engineering (IJAME)

ISSN: 2229-8649 (Print); ISSN: 2180-1606 (Online); Volume 8, pp. 1348-1356, July-December 2013

CUniversiti Malaysia Pahang

DOI: http://dx.doi.org/10.15282/ijame.8.2013.22.0110

\title{
INTERMETALLIC EVOLUTION FOR ISOTHERMAL AGING UP TO 2000 HOURS ON Sn-4Ag-0.5Cu AND Sn-37Pb SOLDERS WITH Ni/Au LAYERS
}

\author{
M.A. Azmah Hanim ${ }^{1,5^{*}}$, A. Ourdjini ${ }^{2}$, O. Saliza Azlina ${ }^{3}$ and I. Siti Rabiatul Aisha ${ }^{4}$ \\ ${ }^{1}$ Department of Mechanical and Manufacturing Engineering, Faculty of Engineering, \\ Universiti Putra Malaysia, 43400 Serdang, Selangor \\ *Email: azmah@eng.upm.edu.my \\ Phone: +60389464387; Faks: +60386567122 \\ ${ }^{2}$ Faculty of Mechanical Engineering, University Technology Malaysia, \\ 81310 Skudai, Johor. \\ ${ }^{3}$ Faculty of Mechanical \& Manufacturing Engineering, \\ Universiti Tun Hussein Onn Malaysia, 86400 Batu Pahat, Johor. \\ ${ }^{4}$ Faculty of Mechanical Engineering, Universiti Malaysia Pahang, \\ 25000 Kuantan, Pahang. \\ ${ }^{\mathbf{5}}$ Laboratory of Biocomposite Technology, Institute of Tropical Forestry and Forest \\ Products (INTROP), University Putra Malaysia, 43400 Serdang, Selangor.
}

\begin{abstract}
The reliability of a solder joint is closely related to the intermetallic compound formation during the joining process and its evolution after exposure to heat. Throughout this paper, interfacial reactions between $\mathrm{Sn}-4 \mathrm{Ag}-0.5 \mathrm{Cu}$ solders and $\mathrm{Sn}$ $37 \mathrm{~Pb}$ solders with electroless nickel immersion gold $(\mathrm{Ni} / \mathrm{Au})$ surface finish were studied. The parameters include the solder type, thickness of the nickel layer and aging time. The results are focused on the type of intermetallic compound formed and the intermetallic thickness. Overall, aging changed the intermetallic morphology to become rounder, bigger and more compact with time. Aged $\mathrm{Sn}-4 \mathrm{Ag}-0.5 \mathrm{Cu}$ solders on $\mathrm{Ni} / \mathrm{Au}$ exhibit the tendency for the intermetallic to change from $(\mathrm{Cu}, \mathrm{Ni})_{6} \mathrm{Sn}_{5}$ to $(\mathrm{Ni}, \mathrm{Cu})_{3} \mathrm{Sn}_{4}$ and finally $\mathrm{Ni}_{3} \mathrm{Sn}_{4}$. The results also showed that, with the parameters used in this experiment, a nickel thickness of $3 \mu \mathrm{m}$ is adequate to be a good diffusion barrier up to 2000 hours aging time. In $\mathrm{Sn}-37 \mathrm{~Pb}$, redeposition of $(\mathrm{Au}, \mathrm{Ni}) \mathrm{Sn}_{4}$ intermetallic starts after 500 hours until 2000 hours.
\end{abstract}

Keywords: Ni/Au, lead free solders; isothermal aging; interfacial reaction; Sn-4Ag$0.5 \mathrm{Cu} ; \mathrm{Sn}-37 \mathrm{~Pb}$.

\section{INTRODUCTION}

In the industry, the term 'flip chip' refers to an electronic component or semiconductor device that can be mounted directly onto a substrate, board, or carrier in a face-down manner. The complexity of wiring closely spaced contact pads is eliminated in flip chip technology (Gilleo \& Vardaman, 2002). Electroless nickel immersion gold (Ni/Au) is a well established surface finish that has been used for many years in flip chip technology. In this system, the nickel layer acts as a diffusion barrier to copper and is the surface to which the soldering or reflow occurs. The function of the immersion gold is to protect nickel from oxidation or passivation during storage (Coombs, 2001; Yoon et al., 2011). The reaction products from the reflow process between the surface finish and the solders are called intermetallic compounds. This intermetallic layer or diffusion zone has a 
profound effect on the mechanical properties of the soldered joint and on its behavior during service (Coombs, 2001; Strauss, 1994). Previous studies have shown that the intermetallic compounds formed are mainly influenced by the type of solders used, the surface finishes involved, and the heat cycle that the interconnection is exposed to (Azmah Hanim et al., 2013; Chen et al., 2006; Huang et al., 2006; Laurila et al., 2005; Yoon et al., 2011). The common industrial solder used in flip chip is Sn-37Pb solder. However, the Restriction of Hazardous Substances in Electronic and Electrical Equipment Directive as agreed by the European Parliament and Council, required lead $(\mathrm{Pb})$ to be phased out starting in July 2006 (Yamada et al., 2006). This sparked the need for a database of lead-free solder's interfacial reaction with the different type of surface finishes available in the market. In this research, the impact of isothermal aging was studied to further understand the growth behavior of intermetallics in terms of their element composition, morphology and thickness when exposed to up to 2000 hours of isothermal aging, with a comparison of the intermetallics formed between $\mathrm{Sn}-4 \mathrm{Ag}$ $0.5 \mathrm{Cu}$ solders and $\mathrm{Sn}-37 \mathrm{~Pb}$ solders on $\mathrm{Ni} / \mathrm{Au}$ surface finish with the parameters given.

\section{EXPERIMENTAL SETUP}

High phosphorus electroless nickel with $9 \%$ wt phosphorus content and more is used in this research. The electroless nickel solutions undergo optimization of the plating process to obtain the desired deposit thickness by varying the plating time. Table 1 shows the combination of chemicals used for the high phosphorus electroless nickel bath.

Table 1. Combination for high phosphorus electroless nickel plating bath solutions (Henry, 1984).

\begin{tabular}{ll}
\hline Item & Quantity \\
\hline Nickel sulfate & $28 \mathrm{~g} / \mathrm{L}$ \\
Sodium acetate & $17 \mathrm{~g} / \mathrm{L}$ \\
Sodium hypophosphite & $24 \mathrm{~g} / \mathrm{L}$ \\
Thiourea & $1.5 \mathrm{mg} / \mathrm{L}$ \\
PH & 4.4 \\
Temperature & $88^{\circ} \mathrm{C}$ \\
P \% & $>10 \% \mathrm{wt}$ \\
Plating time vs thickness & $10 \mathrm{~min} \sim 3.1 \mu \mathrm{m}$ \\
& $20 \mathrm{~min} \sim 6.5 \mu \mathrm{m}$ \\
\hline
\end{tabular}

After the electroless nickel and the immersion gold plating process was completed on the bare copper board, a thin layer of flux was applied to remove the oxides directly before the pads were populated with solder spheres. The reflow process was carried out in a furnace with peak temperature set at $250^{\circ} \mathrm{C}$ for $\mathrm{Sn}-4 \mathrm{Ag}-0.5 \mathrm{Cu}$ solders and $216^{\circ} \mathrm{C}$ for $\mathrm{Sn}-37 \mathrm{~Pb}$ solders. After reflow, both the cross-section and top surface from the samples were then prepared and examined by means of optical and scanning electron microscopy. Energy dispersive x-ray (EDX) was used to identify the type and composition of the intermetallics formed. Both an image analyzer and scanning electron microscopy (SEM) were used to measure the average thickness and examine the morphology of the intermetallics formed. 


\section{RESULTS AND DISCUSSION}

The nickel layer was deposited with two different thicknesses: around $6 \mu \mathrm{m}$ and $3 \mu \mathrm{m}$. This was to compare the effect of different nickel thicknesses on intermetallic formation and to determine whether $3 \mu \mathrm{m}$ nickel is thick enough to act as a diffusion barrier even after extended exposure to high temperature. Two types of solder were used; Sn-4Ag$0.5 \mathrm{Cu}$ and $\mathrm{Sn}-37 \mathrm{~Pb}$ eutectic solder. First, the top surfaces of the intermetallic were compared using SEM. Figures 1 and 2 shows the intermetallic evolution between Sn$4 \mathrm{Ag}-0.5 \mathrm{Cu}$ solder and $\mathrm{Ni} / \mathrm{Au}$ surface finish with $3 \mu \mathrm{m}$ nickel thickness. From these two figures, it can be seen that the aging treatment transforms the intermetallic layer into rounder, bigger and more compact grains over the entire area of the solder bump. The effect is more obvious as the aging time increases. Aside from these effects on the morphology of the intermetallic, the type of intermetallic formed also changed. Basically, the evolution of the intermetallic types are: $(\mathrm{Cu}, \mathrm{Ni})_{6} \mathrm{Sn}_{5} \rightarrow(\mathrm{Ni}, \mathrm{Cu})_{3} \mathrm{Sn}_{4} \rightarrow$ $\mathrm{Ni}_{3} \mathrm{Sn}_{4}$. The change in intermetallic type depends on the availability of copper and nickel atoms.
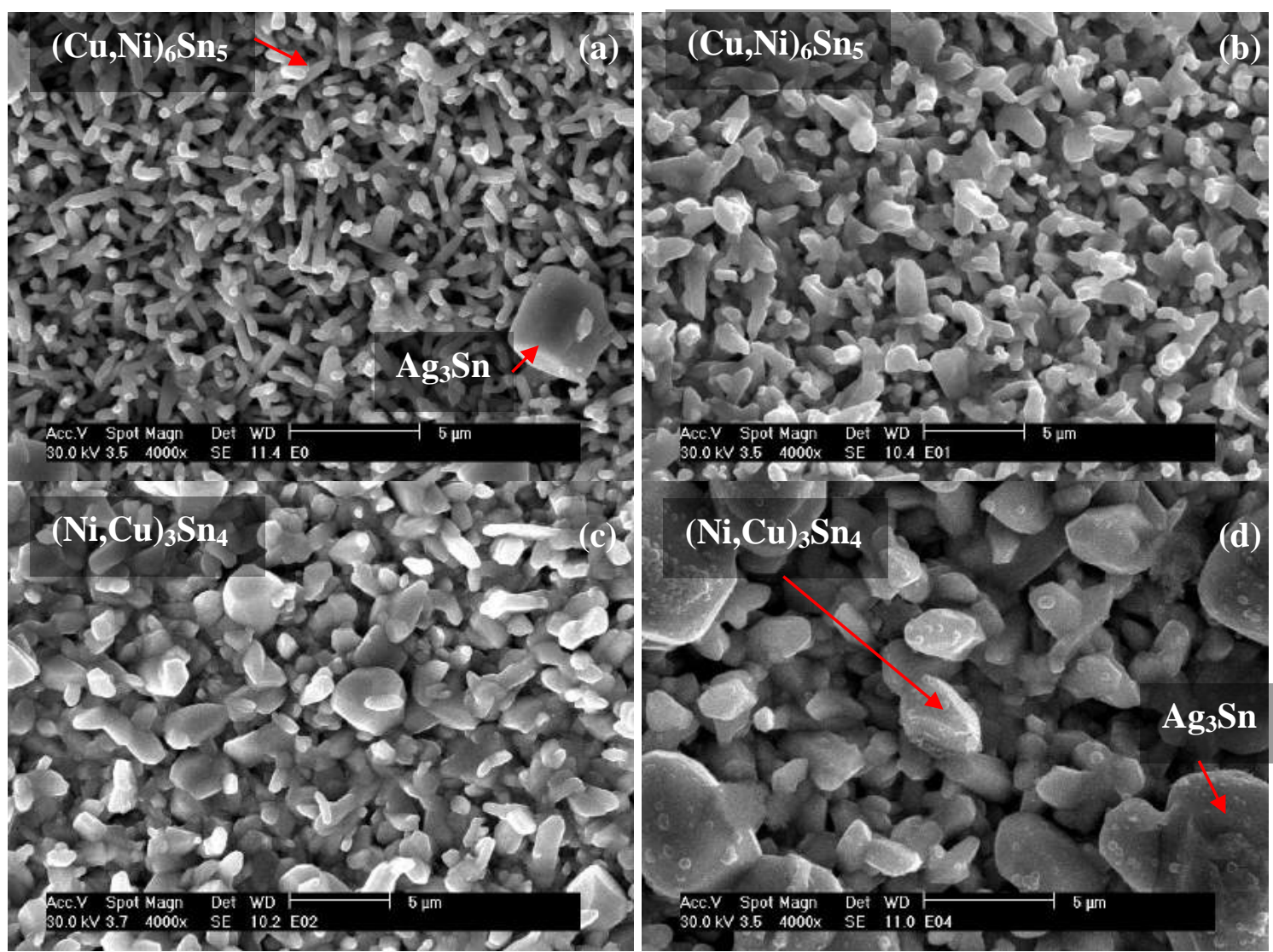

Figure 1. SEM top surface morphology of intermetallic between $\mathrm{Ni} / \mathrm{Au}$ ( $3 \mu \mathrm{m}$ nickel) /Sn-4Ag-0.5Cu solder. Intermetallic is taken in a region near the center of the solder joint: a) after reflow, b) 500 hours aging, c) 1000 hours aging, and d) 2000 hours aging.

At first, during reflow, $(\mathrm{Cu}, \mathrm{Ni})_{6} \mathrm{Sn}_{5}$ formed because the copper content in the solder is $0.5 \%$ which is enough to form this type of intermetallic, as in agreement with other research findings (Yoon \& Jung, 2005; Yoon et al., 2005; Azmah Hanim et al., 
2013). After aging for 1000 hours the intermetallic changes to $(\mathrm{Ni}, \mathrm{Cu})_{3} \mathrm{Sn}_{4}$ because the copper content in the solder has decreased to a certain level. From the EDX analysis the ratio of nickel to copper is higher. However, since the copper percentage is still not too low, the copper element still plays a part in the intermetallic formation. After 2000 hours, the intermetallic changes to $\mathrm{Ni}_{3} \mathrm{Sn}_{4}$. During this time, the copper percentage has decreased to a very low value that is not enough to take part in the interfacial reaction.
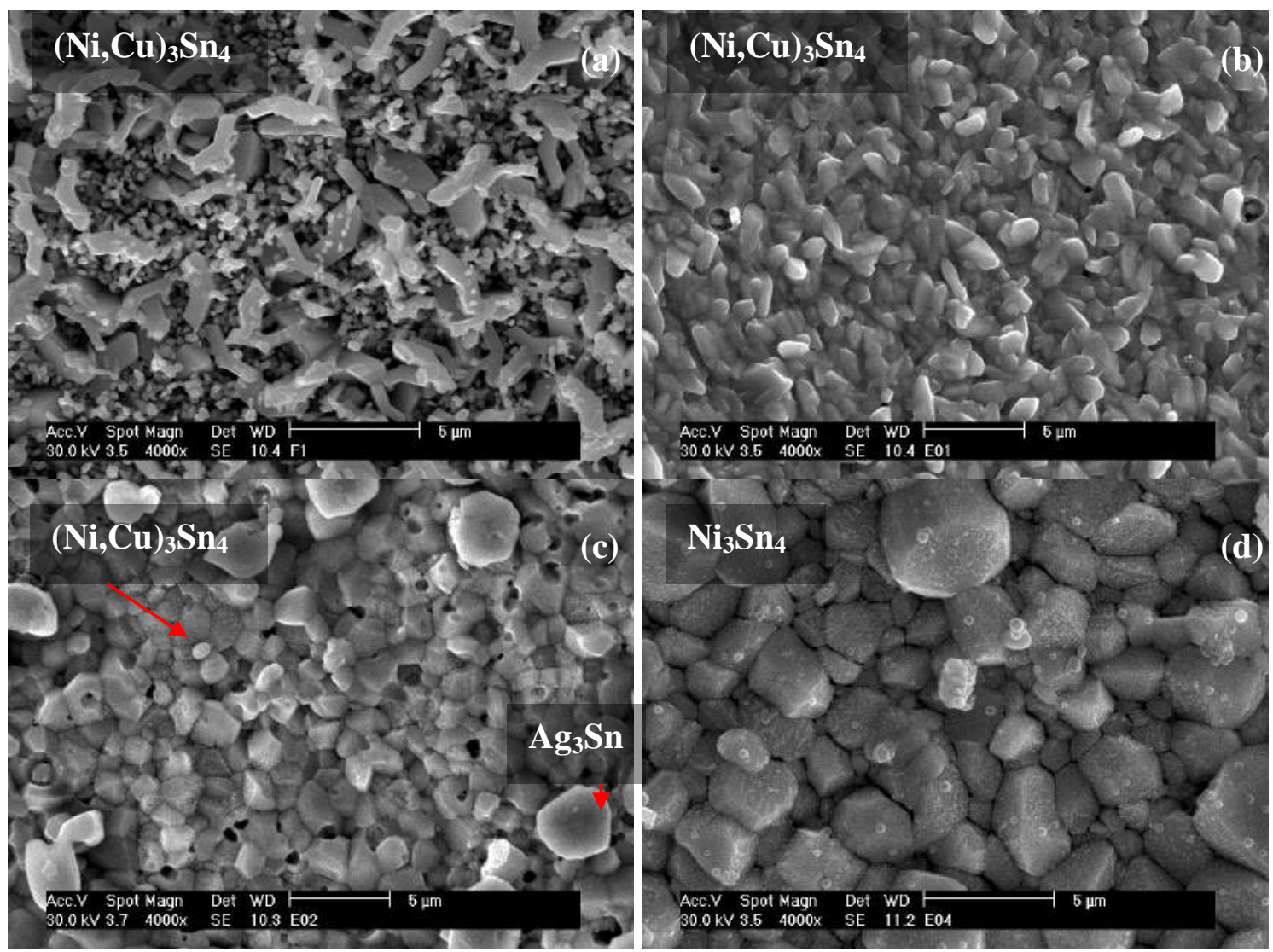

Figure 2. SEM top surface morphology of intermetallic between $\mathrm{Ni} / \mathrm{Au}$ ( $3 \mu \mathrm{m}$ nickel) $/ \mathrm{Sn}-4 \mathrm{Ag}-0.5 \mathrm{Cu}$ solder. Intermetallic is observed in regions near the edge of the solder joint: a) after reflow, b) 500 hours aging, c) 1000 hours aging and d) 2000 hours aging.

Analysis of the samples with $6 \mu \mathrm{m}$ of electroless nickel yield the same results as the $3 \mu \mathrm{m}$ thickness nickel in terms of the type and morphology of the intermetallic observed. It can then be concluded that $3 \mu \mathrm{m}$ of electroless nickel is adequate to act as a diffusion barrier between copper substrate and solder alloy. During reflow between the $\mathrm{Sn}-37 \mathrm{~Pb}$ solder and $\mathrm{Ni} / \mathrm{Au}$ surface finish, $\mathrm{Ni}_{3} \mathrm{Sn}_{4}$ intermetallic is formed at the interface. Figure 3 shows the SEM top surface morphology of intermetallic formed in $\mathrm{Sn}-37 \mathrm{~Pb}$ solder. Aging also induced changes in the intermetallic morphology to become more rounded and compact with bigger grains. As shown in Figure 4, aging of the solder joints using both $\mathrm{Sn}-4 \mathrm{Ag}-0.5 \mathrm{Cu}$ lead-free and $\mathrm{Sn}-37 \mathrm{~Pb}$ solder results in the redeposition of $\mathrm{Au}-\mathrm{Sn}$ intermetallic at the interface. These results are in agreement with previous studies (Laurila et al., 2005; Labie et al., 2006). 

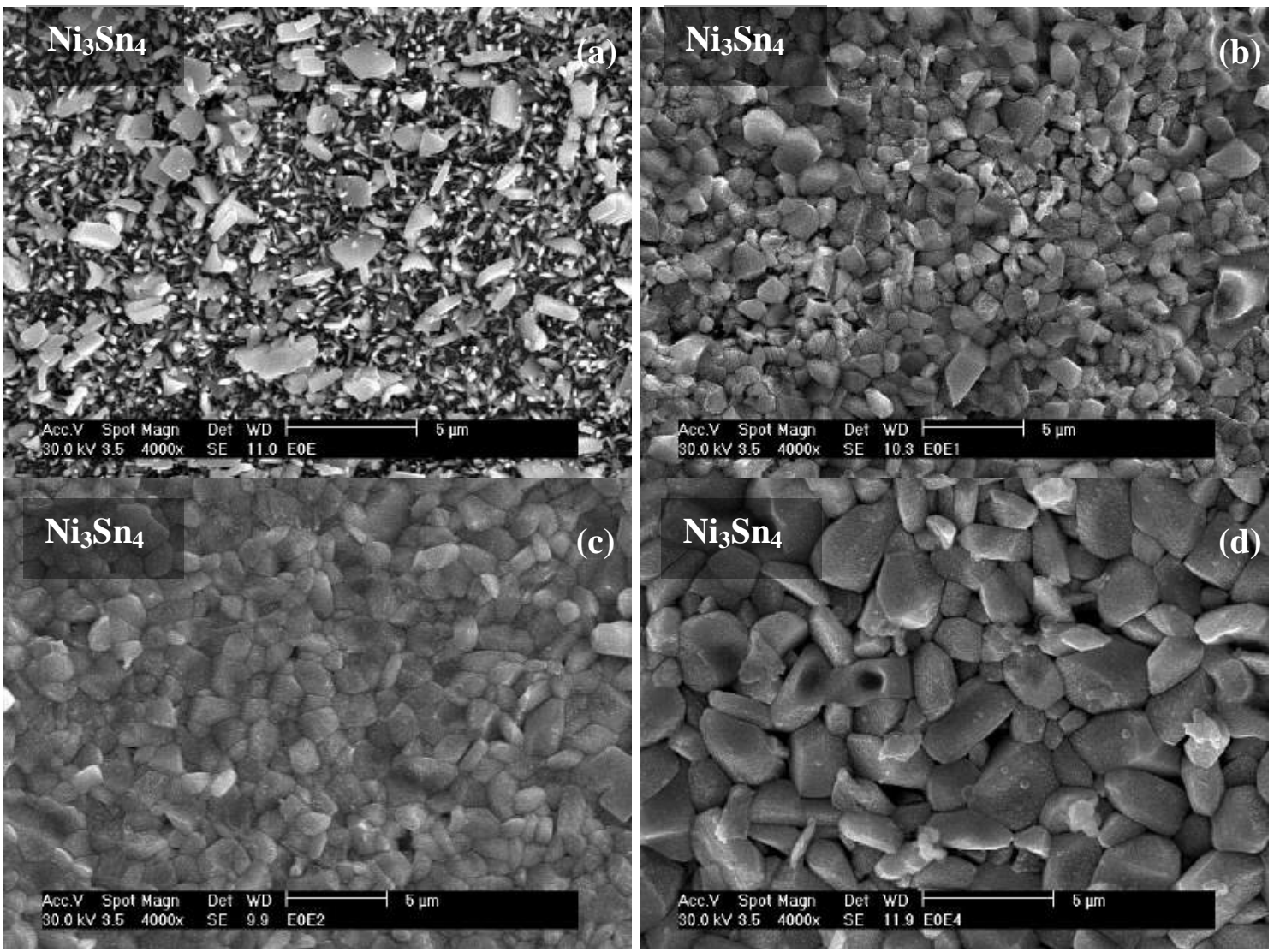

Figure 3. SEM top surface of Ni/Au with $3 \mu \mathrm{m}$ nickel thickness, reflowed with $\mathrm{Sn}-37 \mathrm{~Pb}$ eutectic solder, mag 4000x: (a) as reflow, (b) 500 hours aging, (c) 1000 hours aging, and (d) 2000 hours aging.
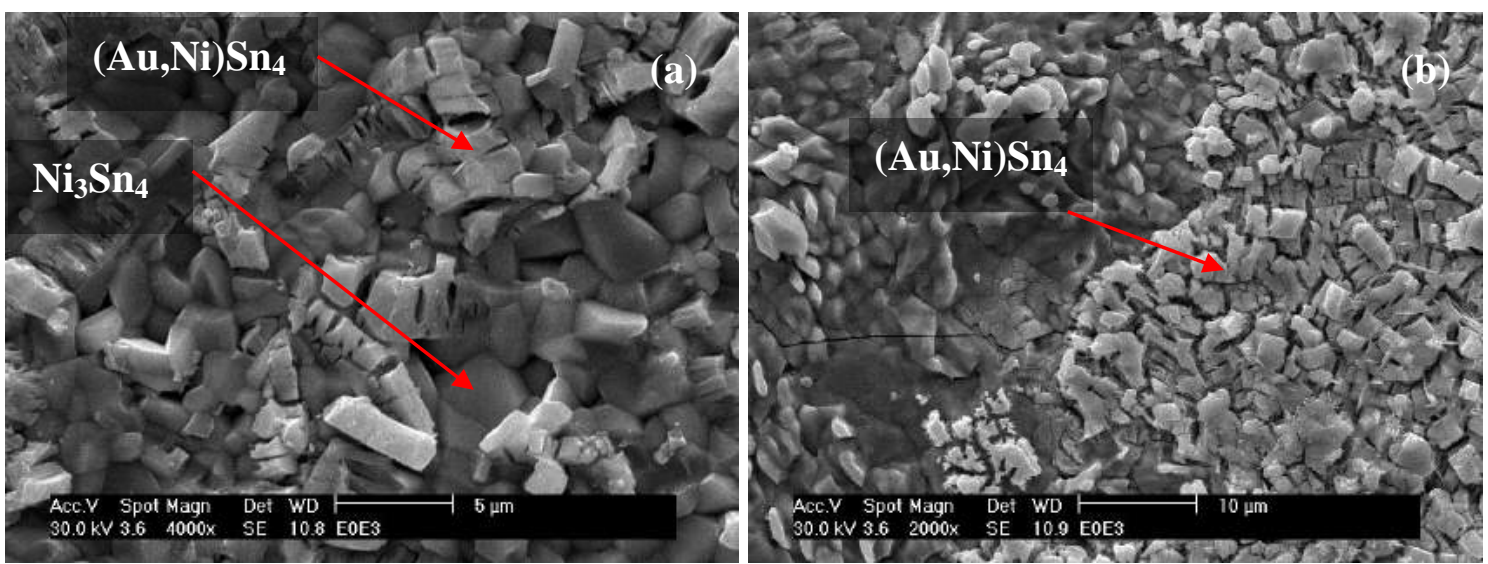

Figure 4. Formation of Au-Sn intermetallic at interface after aging for Ni/Au with $\mathrm{Sn}$ $37 \mathrm{~Pb}$ eutectic solder and $\mathrm{Sn}-4 \mathrm{Ag}-0.5 \mathrm{Cu}$ solder: (a) $\mathrm{Sn}-37 \mathrm{~Pb}$ eutectic solder after aging 1500 hours at $150^{\circ} \mathrm{C}$, (b) Sn-37Pb eutectic solder after aging 1500 hours at $150^{\circ} \mathrm{C}$, and (c) Sn-4Ag-0.5Cu solder after aging 2000 hours at $150^{\circ} \mathrm{C}$. 


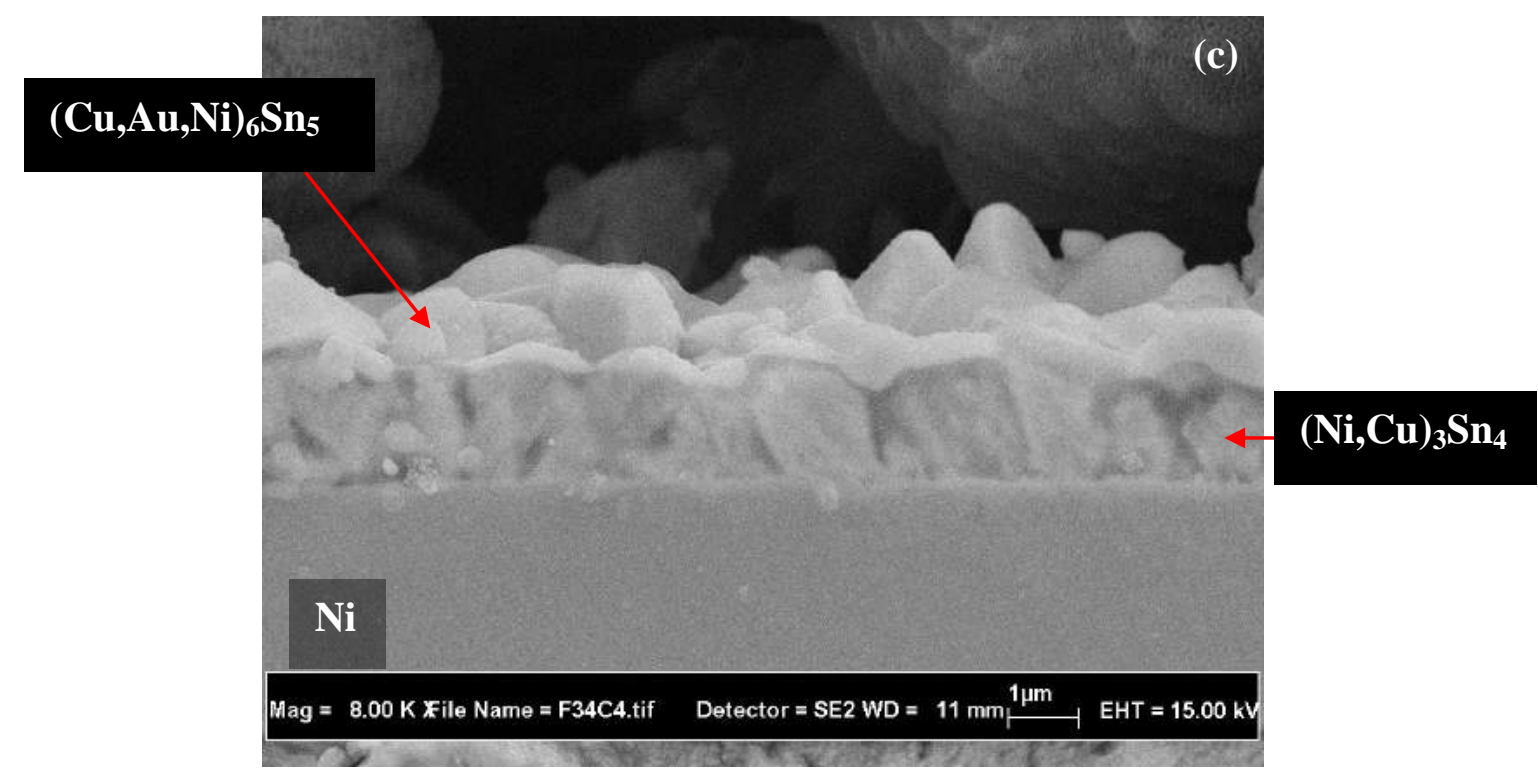

Figure 4 (Cont.). Formation of Au-Sn intermetallic at interface after aging for $\mathrm{Ni} / \mathrm{Au}$ with $\mathrm{Sn}-37 \mathrm{~Pb}$ eutectic solder and $\mathrm{Sn}-4 \mathrm{Ag}-0.5 \mathrm{Cu}$ solder: (a) $\mathrm{Sn}-37 \mathrm{~Pb}$ eutectic solder after aging 1500 hours at $150^{\circ} \mathrm{C}$, (b) Sn-37Pb eutectic solder after aging 1500 hours at $150^{\circ} \mathrm{C}$, and (c) Sn- $4 \mathrm{Ag}-0.5 \mathrm{Cu}$ solder after aging 2000 hours at $150^{\circ} \mathrm{C}$.

Figure 5 shows that for all samples, the intermetallic thickness increases as the aging time increases. As we go into detail for each type of solder, it can also be seen that for the lead-free solder, the $6 \mu \mathrm{m}$ electroless nickel gives thicker intermetallic compared to the $3 \mu \mathrm{m}$ electroless nickel up until 500 hours. After 1000 hours, the growth rate of the $3 \mu \mathrm{m}$ electroless nickel increases rapidly until 2000 hours of aging.

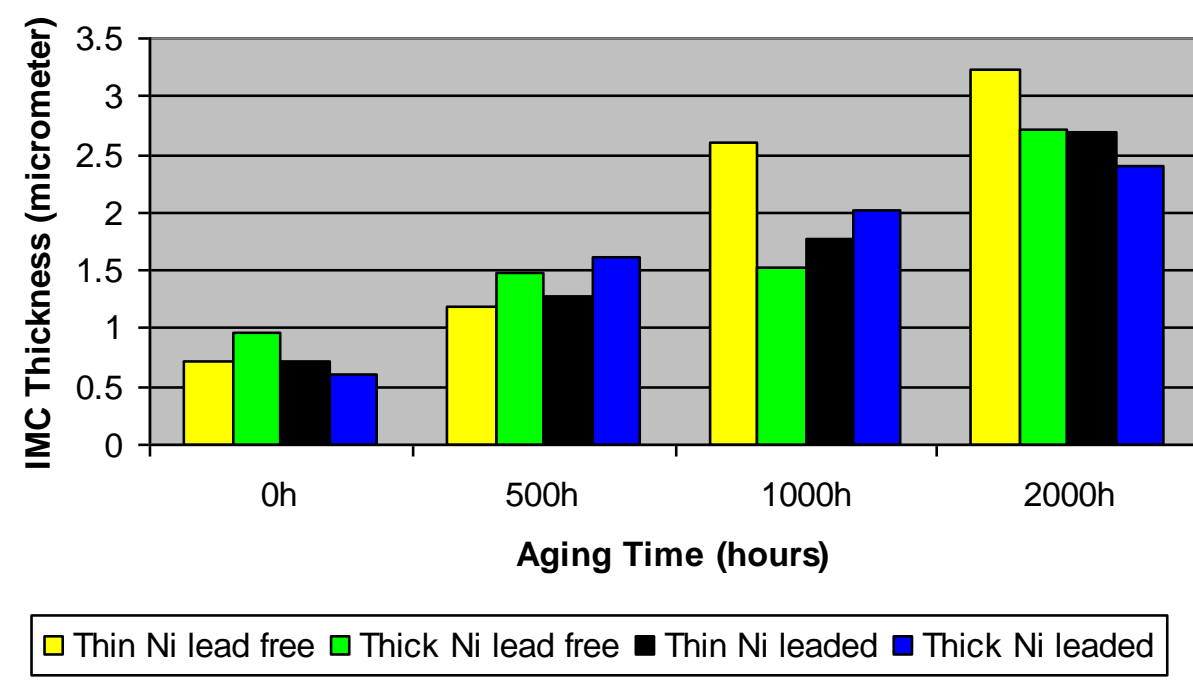

Figure 5. Intermetallic thickness for $\mathrm{Ni} / \mathrm{Au}$ with and without aging at $150^{\circ} \mathrm{C}$, reflowed with $\mathrm{Sn}-4 \mathrm{Ag}-0.5 \mathrm{Cu}$ and $\mathrm{Sn}-37 \mathrm{~Pb}$ eutectic solder.

Comparison of the intermetallic thickness of reflowed and aged solder joints made with the $\mathrm{Sn}-37 \mathrm{~Pb}$ and $\mathrm{Sn}-4 \mathrm{Ag}-0.5 \mathrm{Cu}$ lead-free solders shows that after reflow the 
intermetallic growth is faster in the lead-free solder than in the leaded solder. But, with extended aging at $150^{\circ} \mathrm{C}$ for up to 2000 hours the intermetallic growth on the lead-free solder is slowed down to be surpassed by the leaded solder. According to Huang in 2006, during aging, in order for the $\left(\mathrm{Cu}, \mathrm{Ni}_{6} \mathrm{Sn}_{5}\right.$ intermetallic layer to grow, the copper atoms must diffuse over a long distance from the bulk solder to the interface, which slows down the growth rate of this $(\mathrm{Cu}, \mathrm{Ni})_{6} \mathrm{Sn}_{5}$ layer (Huang et al., 2006). As shown in the top surface views, more $(\mathrm{Cu}, \mathrm{Ni})_{6} \mathrm{Sn}_{5}$ was detected at the interface of the solder joints aged for 2000 hours at $150^{\circ} \mathrm{C}$. Figures 6 and 7 show the cross-section pictures on the aging effect from a side view.
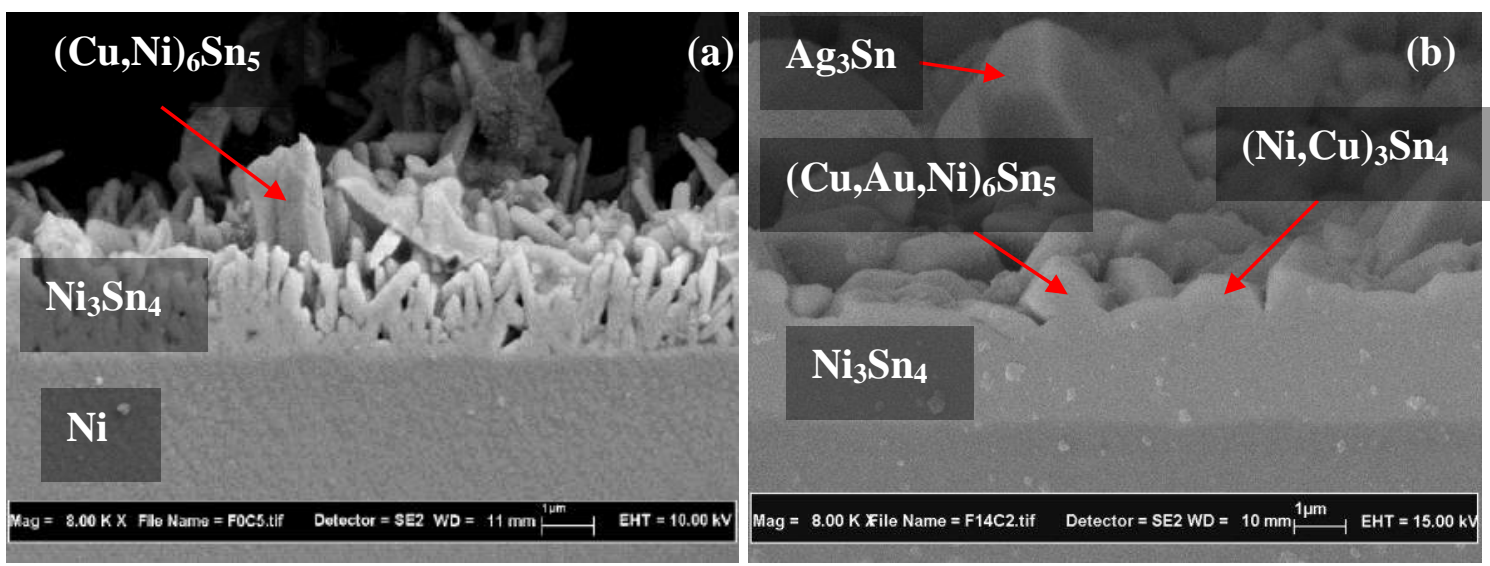

Figure 6. Cross-section micrographs of intermetallic at interface between Ni/Au/ $\mathrm{Sn}$ 4Ag-0.5Cu solder: a) after reflow, and b) aged for 2000 hours.
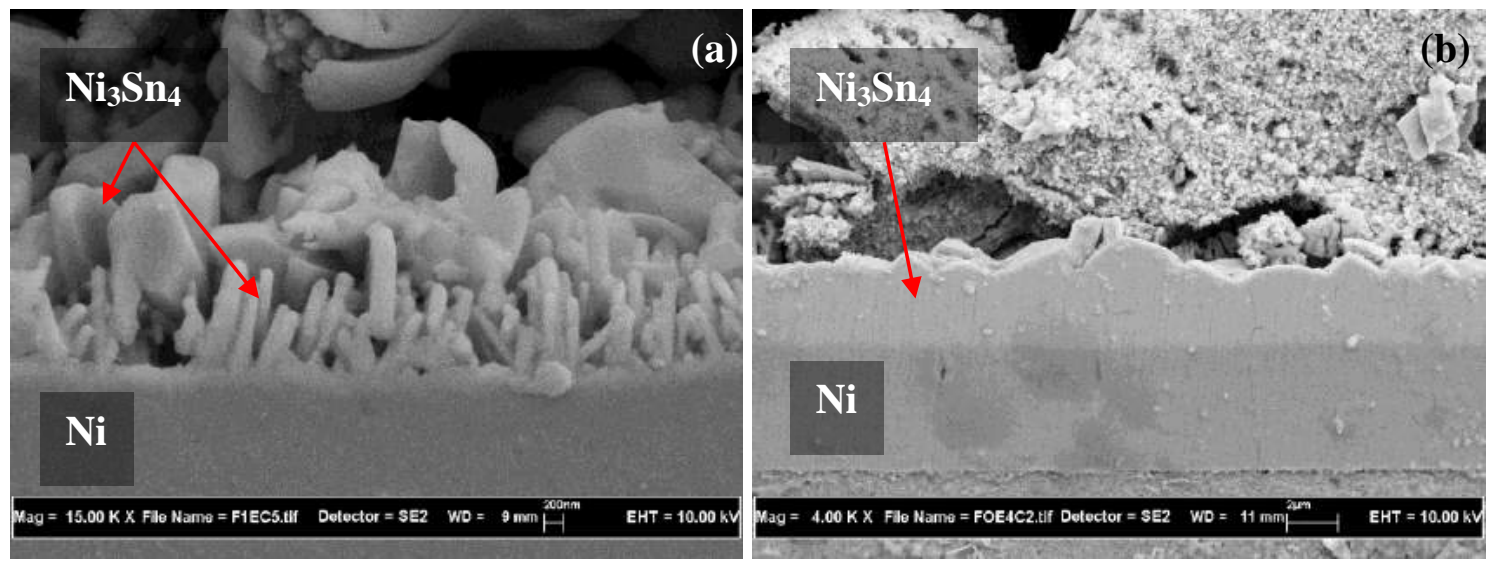

Figure 7. Cross-section pictures for $\mathrm{Ni} / \mathrm{Au} / \mathrm{Sn}-37 \mathrm{~Pb}$ eutectic solder: a) after reflow, and b) aged for 2000 hours.

The intermetallic layer has a planarization tendency during isothermal aging (Azmah Hanim et al., 2013; Xia et al., 2006; Chen et al., 2006). Morphology transition is due to the reduction in surface-free energy. Scallop-like morphology (lots of peaks and valleys) intermetallics have a larger surface area than a planar layer of similar thickness, resulting in a large driving force for surface energy change. Because of the shorter diffusion distance between valleys and copper substrate, compared to the distance between the peak and copper substrate, copper diffuses faster to the valley than 
to the peak, leading to a faster growth rate at the valley and subsequent planarization of the whole intermetallics layer. This theory is proven when we compare the crosssectional views of the joints after reflow with those after aging for both leaded and lead free solders.

\section{CONCLUSION}

This research investigated the effect of aging time at $150^{\circ} \mathrm{C}$ from 500 hours to 2000 hours on a high phosphorus nickel layer with $3 \mu \mathrm{m}$ and $6 \mu \mathrm{m}$ nickel thickness for $\mathrm{Ni} / \mathrm{Au}$ surface finish on the formation of intermetallics compound when reflowed with Sn$4 \mathrm{Ag}-0.5 \mathrm{Cu}$ and $\mathrm{Sn}-37 \mathrm{~Pb}$ solders. It was found that aging changes the intermetallic to become more rounded, bigger and compact. This effect is more pronounced as we increase the aging time. In the cross-sections, aging changes the morphology of IMC from scallop-like to a planar layer of intermetallic. For lead-free solder, the intermetallic type changes from $(\mathrm{Cu}, \mathrm{Ni})_{6} \mathrm{Sn}_{5} \rightarrow(\mathrm{Ni}, \mathrm{Cu})_{3} \mathrm{Sn}_{4} \rightarrow \mathrm{Ni}_{3} \mathrm{Sn}_{4}$ as the aging time increases. This is because the formation of intermetallic for lead-free solder depends on the availability of copper and nickel. As the aging time increases, the amount of copper from the solder reduces because most of it was consumed during the formation of the intermetallic. Different nickel thicknesses in electroless nickel immersion gold do not influence the intermetallic top surface formation. A nickel thickness of $3 \mu \mathrm{m}$ is adequate to be a good diffusion barrier up until 2000 hours of aging at $150^{\circ} \mathrm{C}$. Redeposition of $\mathrm{Au}-\mathrm{Sn}$ intermetallic occurs in leaded samples. The Au-Sn intermetallic was known as $(\mathrm{Au}, \mathrm{Ni}) \mathrm{Sn}_{4}$. The redeposition started after aging for 500 hours and increases as we increase the aging time.

\section{ACKNOWLEDGMENTS}

This research and publication was supported by Intel Technology Malaysia, University Technology Malaysia and University Putra Malaysia.

\section{REFERENCES}

Azmah Hanim, M. A., Ourdjini, A., Siti Rabiatul Aisha, I., \& Saliza Azlina, O. (2013). Effect of isothermal aging 2000 hours on intermetallics formed between Ni-Pd$\mathrm{Au}$ with Sn-4Ag-0.5Cu solders. Journal of Advanced Materials Research. 650, 194-199.

Chen, H. T., Wang, C. Q., Yan, C., Li, M. Y., \& Huang, Y. (2006). Cross-interaction of interfacial reactions in $\mathrm{Ni}(\mathrm{Au} / \mathrm{Ni} / \mathrm{Cu})-\mathrm{SnAg}-\mathrm{Cu}$ solder joints during reflow soldering and thermal aging. Journal of Electronic Materials, 36(10), 1405.

Coombs, C. F. (2001). Coombs' printed circuits handbook (5th ed.). New York: McGraw-Hill.

Gilleo, K. \& Vardaman, J. (2002). Area array packaging handbook: manufacturing and assembly. New York: McGraw-Hill.

Henry, J. (1984). Electroless plating. Part IV-Other metals \& composites. Rock Island: Wear-Cote International.

Huang, Z., Conway, P. P., Jung, E., Thomson, R. C., Liu, C., Loeher, T., \& Minkus, M. (2006). Reliability issues in Pb-free solder joint miniaturization. Journal of Electronic Materials, 35(9), 1761-1772. 
Labie, R., Ruythooren, W., \& Van Humbeeck, J. (2006). Solid state diffusion in Cu-Sn and $\mathrm{Ni}$-Sn diffusion couples with flip-chip scale dimensions. Journal of Intermetallics, 15(3), 396-403.

Laurila, T., Vuorinen, V., \& Kivilahti, J. K. (2005). Interfacial reactions between leadfree solders and common base materials. Materials Science and Engineering $R$. Report, 49(1-2), 1-60.

Strauss, R. (1994). Surface mount technology. Butterworth-Heinemann.

Xia, Y., Xie, X., \& Lu, C. (2006). Intermetallic compounds evolution between lead-free solder and cu-based lead frame alloys during isothermal aging. Journal of Material Science, 41, 2359-2364.

Yamada, Y., Takaku, Y., Yagi, Y., Nishibe, Y., Ohnuma, I., Sutou, Y., \& Ishida, K. (2006). Pb-free high temperature solders for power device packaging. Microelectronics Reliability, 46 (9-11), 1932-1937.

Yoon, J. W. \& Jung, S. B. (2005). Interfacial reactions between $\mathrm{Sn}-0.4 \mathrm{Cu}$ solder and Cu substrate with or without ENIG plating layer during reflow reaction. Journal of Alloys and Compounds, 396(1-2), 122-127.

Yoon, J. W., Noh, B. I., Yoon, J. H., Kang, H. B., \& Jung, S. B. (2011). Sequential interfacial intermetallic compound formation of $\mathrm{Cu}_{6} \mathrm{Sn}_{5}$ and $\mathrm{Ni}_{3} \mathrm{Sn}_{4}$ between $\mathrm{Sn}$ $\mathrm{Ag}-\mathrm{Cu}$ solder and ENEPIG substrate during a reflow process. Journal of Alloys and Compounds, 509, L153-L156.

Yoon, J. W., Kim, S. W., \& Jung, S. B. (2005). IMC morphology, interfacial reaction and joint reliability of $\mathrm{Pb}$-free $\mathrm{Sn}-\mathrm{Ag}-\mathrm{Cu}$ solder on electrolytic Ni BGA substrate. Journal of Alloys and Compounds, 392(1-2), 247-252. 